\title{
Predicaments and Countermeasures of Local Government in China Coping with Public Crisis in the Internet Era
}

\author{
Shanshan Li \\ University of Electronic Science and Technology of China \\ Chengdu, China
}

\author{
Wei Liu \\ University of Electronic Science and Technology of China \\ Chengdu, China
}

\author{
Sijia Yang \\ University of Electronic Science and Technology of China \\ Chengdu, China
}

\begin{abstract}
In the Internet era, the high-speed development of new media and rapid dissemination of information have expanded the channels and time limits for people to obtain information, and strengthened the bond of friendship between people. It is convenient for people to supervise the government and jointly rule the country through the Internet. At the same time, the increased social contradictions in the process of Internet's promoting the social transformation also challenge the measures for traditional public crises. However, the dissemination of new media information has particularity, and the situation that government copes with the public crisis has become more severe. In the Internet era, how should the government cope with the new public crisis? How should the government manage the relationship with the Internet? To achieve this goal, the study attempts to think about solutions and proposes some suggestions and countermeasures for the above problems.
\end{abstract}

Keywords-public crisis; new media; public opinion; countermeasures

\section{INTRODUCTION}

Currently, as the economy continues to extend and develop, people live and work in peace and their living standards have been greatly improved. At the same time, people have more requirements for country management and social development, and social contradictions are prominent, and the frequency of public crises is increasing. The rapid development of new media has brought new challenges to the public crisis. In the new media era, a major problem that China's local government should attach great importance to in coping with public crisis is how to face new challenges, how to tackle new problems, and how to prevent new crises. Therefore, we must first correctly understand the current situation and predicaments of the emergency treatment of public crisis in the Internet era. Through understanding the relevant content, we can systematically put forward solutions step by step.

\section{ANALYSIS ON PUBLIC CRISIS RESPONSE OF LOCAL GOVERNMENT IN CHINA IN THE INTERNET ERA}

In the Internet era, the public crisis response measures and early warning system in China have been rapidly established and improved, which basically enables most public crises to be resolved quickly and steadily. However, with the advent of new media, difficult crises once break out in China, and public opinions and rumors spread from all quarters, which warns us all the time, so public crisis management admits of no delay.

\section{A. The Government's Lack of Awareness of the Use of New} Media to Cope with Public Crises

Nowadays, new media is developing rapidly. Once the public crisis occurs, the golden time for government's emergency treatment is no longer four hours but may be only ten minutes. Otherwise, rumors will spread from all quarters, and public opinion may cause social fluctuations and panic. Therefore, the difficulties of public crisis management mainly come from online new media.

The main form of new media is an information communication mode mainly based on information transmission modes with network as the core such as Weibo and WeChat. It has become a new form of life for rapid communication and exchange of information in modern society. The development of new media changes quickly and has a great impact, and the government's use of new media is still limited to the management mode of "control". However, it is not wise to regulate information by means of control and blockade. This way is harmful to public's right to know and discuss matters, increases the public's antipathy and resistance, and then makes them suspect about the government. The government's loss of credibility will cause a crisis of confidence. Once the trust is lost, the government's coping with public crisis events will be under a difficult circumstance.[1] 


\section{B. The Delayed Information of Public Crisis that the Government Has Disclosed}

The right to know is a basic right for the public to understand the information and government. The government should respect it and publish information in a timely manner. Both crisis information and governmental information should be true and fair. The disclosure of government information has become a key element to establish a sunshine and transparent government. The Regulation of Government Information Disclosure of the People's Republic of China proposes that we should improve transparency of the government, guarantee citizens' rights to obtain information, and give full play to the service role of the government. At present, there are some problems that the disclosure of public information is not timely and becomes a mere formality in some regions of China, and some local governments do not act and even act disorderly under the banner of "maintaining stability". [2] In the fortynine departments of the State Council and twenty-nine provinces and municipalities in Annual Report on Government Information Disclosure Work published in 2014, the reported information of thirteen departments of the State Council and ten provinces and municipalities is more detailed, while reports of other departments of the State Council and provinces and municipalities are brief, and are not updated in a timely manner and become formalistic.

The "water robbing event", which occurred on May 12, 2013, was a simple shipwreck event, but it caused public panic due to the delayed disclosure of government information, and left room for the spread of the rumor. The "Xiamen PX Project Incident" in 2007 became serious due to the fact that the government did not cope with public crises and disclose information timely.

\section{The Weak Coping Capacity of Government Using New Media to Deal with Public Crisis}

According to the 2010 CNNIC Internet Survey Report, mobile phones and mobile networks are very significant in the development of China's Internet. Under the background of the Internet era, the government cannot control and block information and everyone has the right to know the information, moreover, the government is no longer the only "gatekeeper" of information. The developed network and popularized new media promotes everyone to collect, publish and disseminate information by relying on correct discrimination ability and to learn to live in the virtual society of the network, however, this has seriously weaken the ability of government as "gatekeeper". Besides, due to the high age of government workers, their ability to use new media is weak and it can be called that "it is difficult for them to keep up with the trend of the times". They may not realize the importance of new media, and are not willing to learn to try new things by relying on their high qualifications. What's more, they just only use the power in their hands to control the new media, and adopt the traditional "hiding and pushing" approach, which eventually causes that the citizens are disgusted with the government worker's behavior, aggravates the evolution of the situation, and leads to a new crisis for government trust. Practice has proved that the gold processing time for public crisis is the first week of the crisis, therefore, in the first "time window", the government can spend the least manpower, material resources and financial resources to solve the problems, otherwise it will be difficult to solve the problems when crisis enters in development period.

In 2009, the "entrapment operation event in Shanghai" has appeared on the network in the pre-crisis period. The click rate was extremely high, and the public opinion spread. However, the parties failed to promptly disclose the information and cause the vicious development of the incident, which damaged the public image of Shanghai municipal government. Therefore, after encountering the adverse news reported by the network, the government should learn the crisis timely, accurately disclose the crisis information, improve its credibility, and correctly handle the public crisis.

\section{ANALYSIS OF PREDICAMENTS IN LOCAL GOVERNMENT'S COPING WITH PUBLIC CRISIS IN CHINA IN THE INTERNET ERA}

In the Internet era, the dissemination speed of information is fast. The information dissemination at home and abroad no longer relies on Pigeon posts, telegrams and letters, and the Internet can send messages in a second. Therefore, after the public crisis, the speed that the government obtains crisis information may be far lower than the people. With the development of new media such as WeChat and Weibo, bad news travels fast. The government cannot quickly control everything after the crisis, which has become a predicament for the government.

\section{A. Analysis of the Predicaments in Laws, Rules and Regulations}

The public crisis response cannot be separated from the protection of laws and regulations, and public crisis management must be based on law in the Internet era. In the reports of the 18th National Congress of the Communist Party of China, it has proposed that we should "strengthen and improve the network construction and sing network theme", therefore, to overcome the crisis, we should perfect the legal system and manage according to the law. The extension of network media is still immature in Chinese legal system, and disseminators are not bound by law and morality for their specific purposes. Moreover, the update of regulation of laws and policies is relatively lagging in real life relative to the network development, and many laws, rules and regulations cannot effectively supervise and manage network media. Therefore, in the ever-changing society, we urgently need to improve laws and regulations system for network media management, and ensure the standardized development of network government platforms such as "microblog on government affairs" and "network politics", to create a harmonious and healthy network environment. In addition to the positive construction and development of the domestic network environment, we should exchange and cooperate with other foreign countries to create a harmonious network environment for them.

For example, the "Facebook Wars" appeared on Sina microblog in the past two years. On Facebook, a well-known foreign exchange website, the war of emoji package regarding 
the so-called "patriotism" between the mainland people and the Taiwanese people reflected the fact that the government lost the control. In addition, such as "Zhou Ziyu event", the patriotic behavior of Chinese people reflected on foreign websites, such as Twitter and Instagram, is also beyond the control of the government. For inland, Sina microblog can be effectively controlled, but for Facebook, Twitter, Instagram and other foreign websites, the government cannot quickly control them and it is difficult to formulate relevant laws and regulations to restrict this, therefore, for foreign media, it is still difficult for the government to effectively monitor and manage them.

\section{B. Analysis of the Predicaments in Thinking Mode}

Lax network atmosphere and unscrupulous network "negative energy" are closely related to the shortcomings in the government's thinking mode. As the saying goes, people who win the hearts of the people have the world, so government officials must change the idea of "official standard" and serve the people. The government should be the watcher of the social environment, defender of social justice, leader of social opinion, effectively control the network information, and reasonably guide it. [3] The government should guard a good pass of "enhancing network supervision and mastering network management" to ensure information security and information standard management. [4] But now, the government has little understanding on the development trend of network public opinion, and it is hard for them to conduct in-depth analysis macroscopically. The government lacks a multi-dimensional thinking mode, has insufficient capability in coping with crisis, and is still limited to a subtlety in network crisis response and management, and its overall crisis response capability needs to be greatly improved.

\section{Analysis of the Predicaments in Technical Capacity}

After the reform and opening up, China has embarked on the journal of Internet and network era, and the government may have some defects in a warning system for public crisis in the era of new media. Everyone in the Internet era is a selfmedia, and has its own ways and means to disseminate information. This makes the government's monitoring for public opinion only limited to the occurrence of public opinion, and cannot seize the key of public opinion in a timely manner. Their use of Internet of Things and big data is still very limited. It is mainly manifested as follows: on the one hand, technology advancement is limited, which cannot prevent the occurrence of public opinion in time, without forward looking; on the other hand, the quality and ability of technicians is weak, and they cannot re-excavate and re-analyze the public opinion data and cannot get valuable information. Under the background of the era of big data, to construct the intelligent city, the government needs to strengthen in-depth cooperation with all parties, provide wide opportunities for airing views, and gather wisdom to prevent risks, control crisis, and manage safety. Of course, this puts higher demands on ability and quality of government staff and technicians[5].

\section{COUNTERMEASURES FOR THE PUBLIC CRISIS OF LOCAL GOVERNMENT IN CHINA IN THE INTERNET ERA}

In the face of the development of the Internet era, the most important thing for local governments is to grasp the crisis point. Certainly, a complete public crisis early warning system must be established. After the occurrence of public crises, we should make a prompt decision to establish a crisis response system, and establish the head responsibility system that is led by one person and contributed by all the people. The press conference must also be held immediately to explain the truth of the matter to the public, so as to avoid erroneous public opinion disrupting the people.

\section{A. Local Government Should Attach Importance to the Construction of Crisis Management Culture}

Robert Heath, a famous American scholar, believes that cultural factors will increase the difficulty of crisis management. Professor Zhang Chengfu, a Chinese scholar, advocates the combination of crisis management and cultural construction. Culture includes the common language, integrated moral concept and value system, and political consciousness and religious beliefs of the public in society. Therefore, under the complex and changeable international environment, in the case of frequent public crises, local governments in China must attach importance to cultural construction and crisis management culture construction. The construction of the crisis management mechanism should be supported by an advanced management culture rooted in national culture. We must pay attention to cultivating a crisis management culture centered on awareness of unexpected development, and fostering the people's spirit of kindness tendency and civic awareness in the face of disasters, which is also an important way to enhance the ability of government crisis management. [6]

\section{B. Strengthening the Specialization and Professionalization of Institutional Personnel in the Internet Era}

In the network virtual society, information dissemination no longer relies on letters and other means, and the fast and efficient combination of receiving and processing information can be realized through the Internet. When the public crisis occurs, the response and management for public opinion has become a highly difficult and skillful job. In order to carry out such work effectively, we must strengthen the construction of professionals and talents in institutions, and establish a group of talented people with high quality, high ability and high thinking. These people must have a firm political stance, be proficient in the theory of journalism and communication, have a high degree of sensitivity and perception, and have strong organizational and coordination capabilities, so as to effectively control the direction of public opinion development and prevent the spread of negative public opinion[7].

A specialized crisis management agency also needs to be established for public crisis emergency management. For example, we should establish a specialized technical center similar to the National Emergency Operations Center for all kinds of sudden public crisis events, and break through the various public crises step by step. This is mainly reflected in 
the fact that professional personnel are let to display their talents fully, and they can exert their maximum effectiveness to provide effective countermeasures for the national public crisis emergency response.

\section{Paying Attention to and Strengthening the Cooperative Governance Mechanism of Multiple Subjects}

The cooperative governance of multiple subjects mainly refers that political parties, governments, social organizations, and the people jointly govern the country. Public crisis management should shift from government's single subject management to cooperative governance of multiple subjects, constituting a "public crisis management mechanism with clear rights and responsibilities dominated by government, participated by multiple subjects,"[8]. The following measures can be adopted:

1) Collecting, processing, and integrating diverse information to give full play the advantages of multiple subjects: The so-called multiple subjects are the effective integration of various forces in the country and society. Therefore, in the process of public crisis management, the various forces should give full play to their respective advantages, effectively integrate information and deal with public crises.

2) Unblocking the channels for multiple subjects to make suggestions and give full play to their strengths in public crisis management: In the process, the government should open its way and attach importance to social forces, thereby enhancing their enthusiasm and initiative in participating in management and giving full play to their ability to participate in public crisis management.

3) Constructing network comprehensive emergency platform:The government should actively build a comprehensive network emergency platform, give an activity section to multiple subjects, and facilitate the participation of all social forces in public crisis management, and improve their enthusiasm [9], so that they can update their handling methods in a timely manner, quickly obtain public interest appeals, and enable the government to better serve the people. This will also help the government and the people to understand each other, communicate with each other, improve the credibility of the government, and build a new China in a faster, higher and stronger way in the Internet era.

\section{CONCLUSION}

In the Internet era, using feedforward control to replace feedback control and enhancing the crisis early warning mechanism to reduce the frequency of crisis and the vicious results brought by public crises is the most important; in the Internet era, establishing a positive interaction between the government, the public, and the new media to enhance communication and cooperation between each other and to coordinate and manage the country is also very important; it is necessary to strengthen the force of supervision for new media, regulate the content of new media communication, and make the Internet well communicate with the government and citizens; the government should pay more attention to the rural situation and improve the living environment in remote areas, so as to narrow the gap between urban and rural areas.

We must grasp the trend of public opinion in online media, let online media serve the government and serve the people better.

\section{REFERENCES}

[1] Zhang Yue. Research on Government's Public Crisis Management in the New Media Era [D]. Changchun University of Technology, 2015.

[2] Same as [1]

[3] Mi Xiao. Mode Adjustment and Mechanism Innovation: Research on Government's Public Crisis Governance in the Network Age [D]. Soochow University, 2014.

[4] Song Lidan. Safeguarding National Ideology Security in the Era of Mobile Network [J]. Red Flag Manuscript, 2015 (6): 9-11.

[5] Wang Xiaolin. The Difficulties and Breakthroughs of the Government in Dealing with the Network Media [D]. Jilin University, 2016.

[6] Huang Jiancheng. Research on Public Crisis Management Strategy of Local Government [D]. Inner Mongolia Normal University, 2016.

[7] Fu Xuesong. Study on the Strategy of Local Governments to Cope with Public Opinions in the Age of Social Media [D]. East China Normal University, 2016.

[8] Zhang Chengfu. Public Disaster Management: Comprehensive and Integrated Model and the Choice of Chinese Strategy [J]. Chinese Public Administration, 2003 (7).

[9] Chen Yongyi. Research on Public Crisis Governance in China in the New Media Age [D]. Nanjing Normal University, 2014. 